\section{CIUDAD Y HÁBITAT INFORMAL: LAS TOMAS DE TERRENO Y LA AUTOCONSTRUCCIÓN EN LAS QUEBRADAS DE VALPARAÍS0 ${ }^{1}$}

Andrea Pino Vásquez ${ }^{2}$ y Lautaro Ojeda Ledesma ${ }^{3}$

\section{Resumen}

El artículo tiene por objetivo evidenciar el fenómeno urbano de las tomas de terrenos en las quebradas de Valparaíso, Chile, las que definen una forma de apropiación particular de estos sectores de la ciudad.

Se revisa el concepto de ciudad informal, con la finalidad de ubicar las tomas de terreno, como parte de las construcciones informales latinoamericanas.

Se presentan los resultados del análisis de entrevistas realizadas a los habitantes de las quebradas, destacando las causas principales que influyeron en la ocupación ilegal de las quebradas: los sucesivos terremotos y la movilidad familiar.

\section{CITY AND INFORMAL HABITAT: ILLEGAL OCCUPATION OF LAND AND SELF-HELP CONSTRUCTION IN THE RAVINES OF VALPARAÍS0 ${ }^{1}$}

Andrea Pino Vásquez², Lautaro Ojeda Ledesma³

\title{
Abstract
}

This paper aims to highlight the urban phenomenon of illegal occupation of land in the ravines of Valparaíso, Chile, being this action an appropriation method common to these areas of the city.

The concept of informal city is revised for the purpose of categorizing the illegal occupation of land within the group of Latin American informal dwellings.

Likewise, this paper offers the findings from interviews to the dwellers of these settlements and reveals the main reasons that led to such occupations: successive earthquakes and family mobility. 
Se desarrolla el concepto de los "Conjuntos residenciales familiares" (C.R.F), forma particular que adquiere la toma o invasión de terreno en las quebradas de Valparaíso. Son realizadas por grupos familiares y corresponden a procesos socio-espaciales evolutivos que influyen en la consolidación de estos espacios urbanos.

\section{PALABRAS CLAVE: QUEBRADAS, TOMAS, HÁBITAT INFORMAL Y VALPARAÍSO.}

Fecha de recepción: 09-03-2012

Fecha de aceptación: 10-05-2013

1 Este artículo es producto de la tesis doctoral "Habitat informel dans les quebradas de Valparaíso dynamiques d'appropriation", Université de Bretagne 0ccidentale, defendida el 7 de diciembre de 2012 y financiada por CONICYT BECAS-Chile.

2 Chile. Arquitecta, Universidad de Valparaíso. Doctor Institut de Géoarchitecture Université de Bretagne 0ccidentale, France. Correo electrónico: andreapino.v@hotmail.com

3 Chile. Arquitecto, Universidad de Valparaíso. Profesor auxiliar, Facultad de Arquitectura, Universidad de Valparaíso. Doctor Institut de Géoarchitecture, Université de Bretagne 0ccidentale, France. Correo electrónico: lautaro.ojeda@uv.cl
Lastly, this contribution develops the concept of "Family Residential Complexes" (FRC), which is the particular name given to the occupation or invasion of land in Valparaíso ravines. This appropriation method is carried out by family groups and represents evolutionary socio-spatial processes that influence the consolidation of these urban spaces.

\section{KEYWORDS: RAVINES, ILLEGAL LAND OCCUPATION, INFORMAL HABITAT, VALPARAÍSO.}

Received: 09-03-2012

Accepted: 10-05-2013

1 This paper is part of the doctoral thesis Informal Habitat in the Ravines of Valparaíso: Appropriation Dynamics, University of Western Brittany. This thesis was defended on December 7, 2012 and was funded by CONICYT BECAS-Chile

2 Chile. Architect, University of Valparaíso. PhD, Institute of Geoarchitecture, University of Western Brittany, France. Email: andreapino.v@hotmail.com

3 Chile. Architect, University of Valparaíso. Assistant Professor, Faculty of Architecture, University of Valparaíso. PhD, Institute of Geoarchitecture, University of Western Brittany, France. Email: lautaro.ojeda@uv.cl 


\section{Introducción}

De manera general, el hábitat informal ha sido observado por instituciones gubernamentales, planificadores e investigadores desde una perspectiva inadecuada, en el sentido que aún se percibe como un problema, ensombreciendo las posibilidades que entrega este hábitat como solución habitacional y como proceso natural de construcción de nuestras ciudades.

Un ejemplo de esto son las quebradas de Valparaíso, territorios que por largos años han sido objeto de estigmatizaciones provenientes tanto de la sociedad en general, como de los estamentos estatales, producto del hábitat informal que ellas presentan. Hábitat informal que entendemos como una realidad socio-espacial compleja y como una producción ex nihilo que busca consolidarse y ser parte de la ciudad.

Es por ello que esta investigación busca revelar las causas y formas de apropiación del hábitat informal, evidenciando cuál es la particular de conformación de la toma en las quebradas de Valparaíso, mediante un enfoque cualitativo e interdisciplinario que moviliza conjuntamente herramientas de la arquitectura y la sociología. El objetivo revelar los procesos sociales y espaciales que influyeron en la ocupación, construcción, transformación y consolidación de estos territorios, determinando una manera particular de apropiación y conformación de la toma de terreno en las quebradas de Valparaíso, que ha definido un modelo arquitectónico informal propio.

Así, se proponen dos hipótesis iniciales que fueron asidas en los primeros trabajos de terrenos y que luego son corroboradas mediante los relatos de vida de los habitantes:

1- El hábitat informal en las quebradas nace de tomas de terreno de carácter individual y/o de pequeños grupos familiares, que obedecen a una lógica de movilidad familiar.

2- Los terremotos están en el origen de la ocupación de las quebradas.

Ambas hipótesis se constituyen como las principales causas de ocupación y a través del tiempo dieron origen a los conjuntos residenciales familiares (C.R.F) de las quebradas de Valparaíso.

\section{Territorio de estudio}

Valparaíso posee a lo menos 42 cerros y por ende innumerables quebradas, es por ello que el territorio de estudio se acotó a aquellas quebradas que se conectaran directamente con el camino Cintura o avenida Alemania (100 m.s.n.m.), y que se extienden hacia el sur de la ciudad limitando con el camino La Pólvora (430 m.s.n.m.). De esta manera se distinguen e identifican 12 quebradas, las cuales denominaremos como quebradas no-consolidadas 
por presentar un estado semi-natural, que debido a la acción antrópica, no planificada, poseen una considerable degradación ambiental.

Estas 12 grandes quebradas fueron clasificadas según tres niveles de consolidación, los cuales hemos evaluado básicamente a partir de cuatro parámetros generales: tipo de tenencia de los sitios; existencia y calidad de las conectividades urbanas; calidad y consolidación de la vivienda; y finalmente el acceso a los servicios básicos. Y determinamos tres niveles de consolidación: primario ${ }^{4}$, secundario 5 y terciario ${ }^{6}$.

Para efectos de los resultados que presentaremos y a partir de esta primera clasificación se realizó una selección de tres quebradas, las cuales representan los tres niveles de consolidación antes explicitados. Quebradas: Las Cañas (primaria), El Litre (terciaria) y Las Chanas (secundaria).

4 Primaria: corresponde a la construcción del refugio básico, asegurando la tenencia del sitio. Puede ser una pieza o una mediagua, construidas con materiales de recuperación y que da cobijo a toda la familia.

5 Secundaria: implica la evolución y mejora de la vivienda, generado por la necesidad de mejorar la calidad de vida y es la etapa donde habitualmente se asegura la tenencia del sitio, es decir, se busca regularizarlos. Existe un acceso a parte de los servicios básicos.

6 Terciaria: la consolidación se revela tanto a nivel de la vivienda, como en el espacio público, el cual logra consolidarse mediante la autogestión de los habitantes. Es decir, existe una preocupación de cómo acceder a la vivienda y cómo ésta se conecta con la ciudad. Se implementa la totalidad de servicios básicos.

\section{Metodología}

Para comprender los procesos y mecanismos socio-espaciales constitutivos del hábitat informal en las quebradas, se realizó un trabajo desde dos perspectivas, una arquitectónica-urbana mediante la realización de croquis, levantamientos planimétricos y fotográficos; y paralelamente una etnosociológica, mediante la recolección de relatos de vida $y$ de encuestas.

La investigación tuvo un carácter emergente, es decir, inicialmente las encuestas nos permitieron balizar el terreno y definir las temáticas a abordar. Sin embargo, los resultados obtenidos a partir de las encuestas no serán presentados en este artículo, sino por el contrario privilegiaremos los relatos de vida por la riqueza de su contenido.?

7 Los trabajos de terreno se realizaron con el financiamiento del Institut de Géoarchitecture. Cada entrevista fue realizada por uno de los investigadores, en la vivienda de cada entrevistado. 
FIGURA 1. DOCE QUEBRADAS NO CONSOLIDADAS.

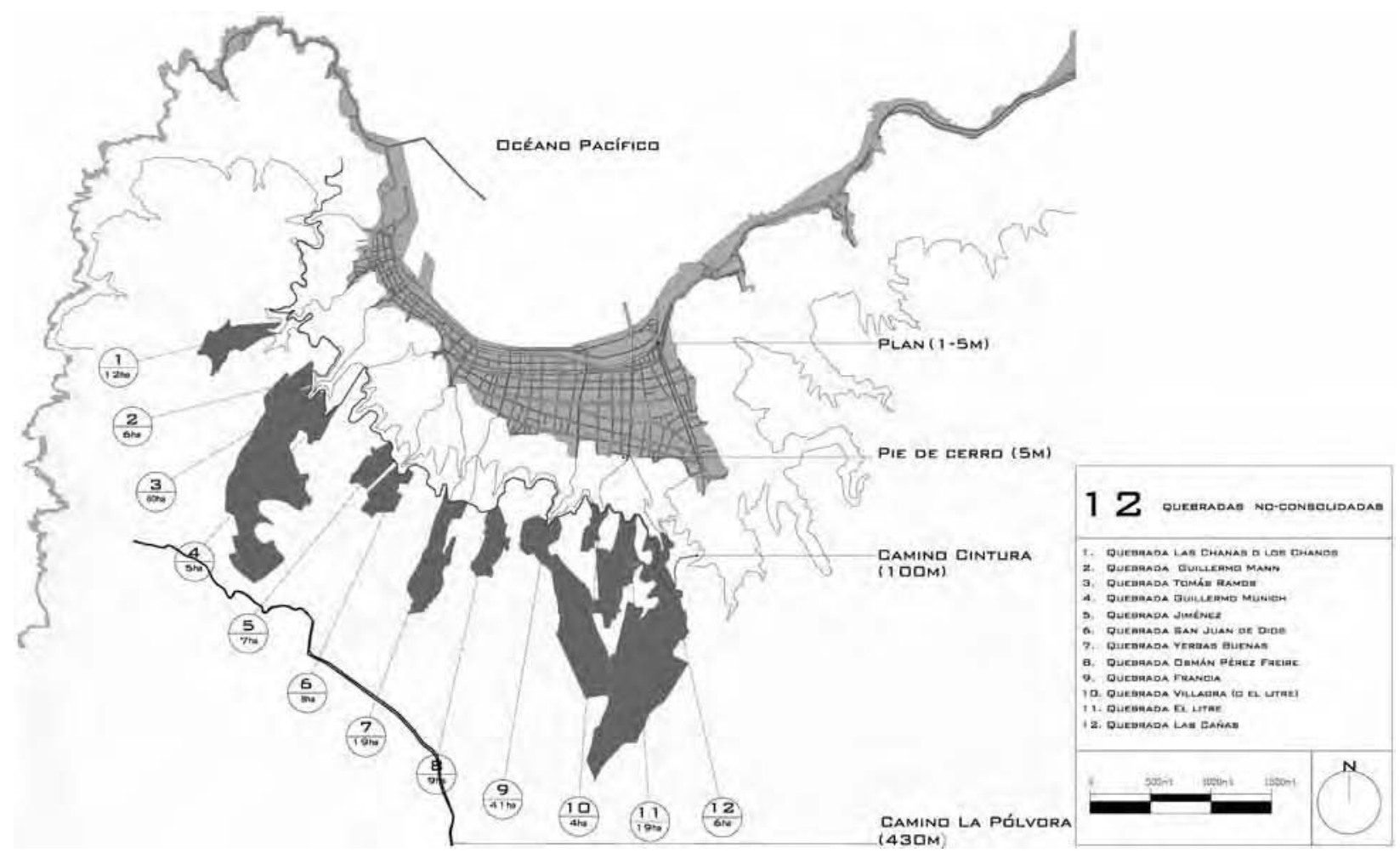

Fuente: Autores 


\section{LOS RELATOS DE VIDA}

Los relatos de vida son una herramienta interdisciplinaria que nace en las ciencias sociales, y que es utilizada particularmente por la sociología, la etnología, la historia y la antropología.

Este método nace de un tipo de entrevista narrativa, "en la cual el investigador solicita a una persona (sujeto) contarle todo o una parte de su experiencia vivida, poniendo el acento sobre el aspecto 'vida social: vida y actividades en relación y en interacción con otras personas". Esta narración realizada por el sujeto nace a partir de una consigna inaugural propuesta por el investigador, en nuestro caso la consigna fue: ¿Podría usted contarme su historia de cómo llegó a vivir a esta quebrada y cómo construyó su casa?

Esta pregunta tiene tres objetivos generales, que fueron profundizados en mayor o menor grado según las experiencias vividas y opiniones de cada entrevistado. Primero, comprender la evolución temporal de ocupación de las quebradas abarcando la historia general del lugar; segundo, descubrir los procesos sociales y materiales de la toma de terreno y de la autoconstrucción y cuál es la forma particular que éstas adquieren en las quebradas; tercero, conocer la organización social al interior de una quebrada y cómo éstas han influido en la consolidación de las mismas.

8

Bertaux, 2010, p. 10.
Ante estos objetivos se establecen cuatro categorías de habitantes informantes: Habitantes Fundadores (HF), Habitantes dirigentes sociales (HD), Habitantes nuevos (HN), Habitantes de C.R.F. (H.C.R.F.).

El número de entrevistados por quebrada fueron 9 en El Litre (1 hombre - 8 mujeres), 10 en Las Cañas (2 hombres - 8 mujeres) y 9 en Las Chanas ( 4 hombres - 5 mujeres). Y el número de entrevistas por el tipo de informantes fueron los siguientes: Habitantes Fundadores (H.F): 4 en El Litre, 4 en Las Cañas y 4 en Las Chanas. Habitantes de Conjuntos Residenciales Familiares (H.C.R.F): 3 en El Litre, 2 en Las Cañas y 3 en Las Chanas. Habitantes Dirigentes Sociales (H.D): 1 en El Litre, 2 en Las Cañas y 1 en Las Chanas. Habitantes Nuevos (H.N): 1 en El Litre, 2 en Las Cañas y 1 en Las Chanas.

\section{EL HÁBITAT INFORMAL DE LA OUEBRADA COMO CONSTRUCCIÓN SOCIAL}

El hábitat informal presente en las quebradas de Valparaíso, en tanto que paisaje es un constructo social en el sentido expresado por Nogué, es decir, es un producto social que resulta de una proyección cultural sobre un espacio determinado y explica que "Las sociedades humanas han transformado a lo largo de la historia los originales paisajes naturales en paisajes culturales, caracterizados no sólo por una 
determinada materialidad (formas de construcción, tipos de cultivos), sino también por los valores y sentimientos plasmados en el mismo", y agrega que éstos son construidos y responden a una lógica que busca transmitir una determinada forma de apropiación del espacio. Lefebvre sostiene que "La práctica espacial consiste en una proyección 'sobre el terreno' de todos los aspectos, elementos y momentos de la práctica social"10. Es desde esta perspectiva que consideramos que el hábitat de las quebradas de Valparaíso genera códigos sociales tácitos y explícitos, que determinan una forma particular de apropiación de estos territorios. Guy Di Méo explica que el hábitat "Lejos de reproducir una estricta subjetividad, también refleja los códigos de la sociedad en la cual se inscribe el individuo" "11, expresando una manera particular de sociabilidad. Reeves explica que los barrios informales son originados por la unidad de un grupo social determinado y por las particularidades del terreno donde se emplazan, y que la claridad con la cual se expresa y se desarrolla la sociabilidad se debe al modo de cómo se generó el barrio informal, "que se hace por acreción local de viviendas, sin planificación previa"12.

La construcción social que genera el hábitat informal es la característica común a todos los asentamientos informales de los países latinoamericanos.

9 Nogué, 2007, p. 12

10 Lefebvre, 2000, p. 15.

11 Di Méo, 1998, p. 98.

12 Berenstein Jacques, 2001, p. 22.
Por ejemplo, Bolívar describe los barrios informales de Caracas como el reflejo de "la sumatoria de las múltiples intervenciones y transformaciones que se van produciendo en momentos distintos [...] como una obra en permanente construcción"13, intervenciones que indudablemente son el resultado de un complejo proceso de sociabilización. A su vez, Lindón explica que "la idea de que el territorio es construido socialmente no se refiere al sentido material de la palabra construir, sino que a la construcción de una microsociedad y un territorio por parte de los habitantes locales"14. En relación a las favelas, Jeudy señala que "La arquitectura de las favelas toma toda su relevancia estética en su relación implícita asociada a la vida cultural y social que refleja. Es, sin lugar a dudas, una de las fortalezas de su concepción arquitectónica -sin arquitectos- que hace que el hábitat sea un acto cultural colectivo y singular"15.

El estudio de este fenómeno adquiere una real importancia en las investigaciones urbanas y sociales actuales, donde las temáticas desarrolladas guardan relación con la intención de reintegrar estas formas habitables al medio urbano y sobre su cultura arquitectónica, rescatando sus valores estéticos, sociales y micro-economías, reconociendo en el hábitat informal un carácter y germen de una auténtica arquitectura local.

Bolívar, 1995.

Lindón, 2002, p. 31.

Berenstein Jacques, 2001, p. 7. 


\section{La ciudad informal}

La acelerada expansión de las ciudades latinoamericanas se percibe como un crecimiento descontrolado y desmedido, el cual impone y sobrepasa los márgenes legalmente establecidos ${ }^{16}$. Esto ha generado de cierta forma una ciudad dual ${ }^{17}$ o ciudad bis $^{18}$, donde coexisten la ciudad formal y la ciudad informal o la ciudad legal y la ciudad ilegal ${ }^{19}$.

Fernandes, refiriéndose a los procesos de producción informal de la ciudad, señala que: "este proceso es constituyente del espacio urbano latinoamericano, tratándose de un proceso estructural que, como tal, no está aislado, no constituye una excepción y no se trata de una cuestión exclusiva de las grandes ciudades"20.

En tanto, Borja dice:

"hoy como ayer, una gran parte de la población del mundo vive en hábitats autoconstruidos, en los márgenes, en los intersticios, en las áreas abandonadas de las ciudades pensadas. Esta ciudad sin nombre de ciudad, que no aparece en los planos ni en los planes, responde también a una idea de ciudad por parte de sus autos constructores. Pero es también una prueba de que la

\footnotetext{
16 En Chile, márgenes establecidos por los Planes Reguladores Comunales, y ordenanzas. OGUC y LGUC.

17 Tardin Coelho, 2007.

18 Agier, 1999.

19 Hardoy, 1987.

20 Citado en Ministerio de Vivienda, 2010, p. 35.
}

conquista de la ciudad es también nostalgia de futuro, una conquista humana a medio hacer." 21

Así, por una parte, la ciudad formal estaría conformada por asentamientos legales que cumplen con las leyes y ordenanzas, tanto en los procesos de adquisición de los bienes como en los procesos de construcción de los mismos. Y la ciudad informal estaría conformada por todas aquellas prácticas que se instauran, desarrollan y consolidan fuera de las leyes y ordenanzas, en este caso nos referimos a las formas de apropiación por las cuales se accede al suelo urbano y a la vivienda, desde la adquisición de los terrenos, hasta la autoconstrucción de la vivienda.

Aymonino ${ }^{22}$ propone que se hace ciudad a partir de la simple adición de unidades de viviendas. Así, consideramos que el hábitat informal es otra manera de hacer ciudad, simultánea o paralela a la formal, que debe ser reconocida y valorada en pos de su mejoramiento y/o consolidación. Con respecto a esto, Fernandes agrega que en ciudades como "Sao Paulo y Rio de Janeiro se admite oficialmente que el porcentaje de informalidad urbana se acerca al $50 \mathrm{o}$ $55 \%$, considerándose únicamente los procesos de acceso al suelo y a la vivienda". ${ }^{23}$ 
FIGURA 2. HÁBITAT INFORMAL EN LAS QUEBRADAS.

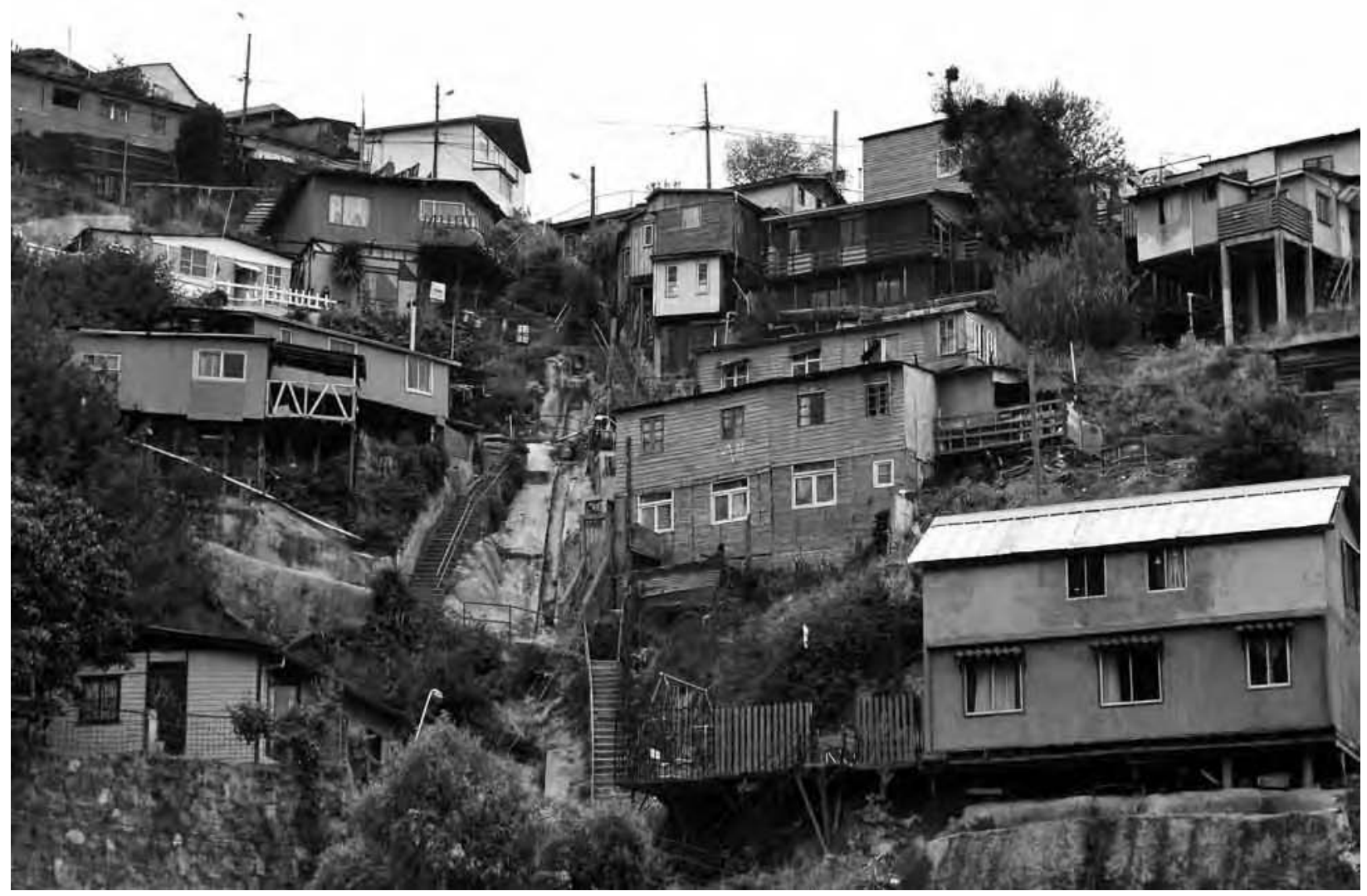

Fuente: Autores

ARTíCULO: Ciudad y hábitat informal: Las tomas de terreno y la autoconstrucción en las quebradas de Valparaíso / Andrea Pino Vásquez, Lautaro Ojeda Ledesma 
FIGURA 3. LA EVOLUCIÓN Y DENSIFICACIÓN DE UN LOTE, QUEBRADA LAS CAÑAS.

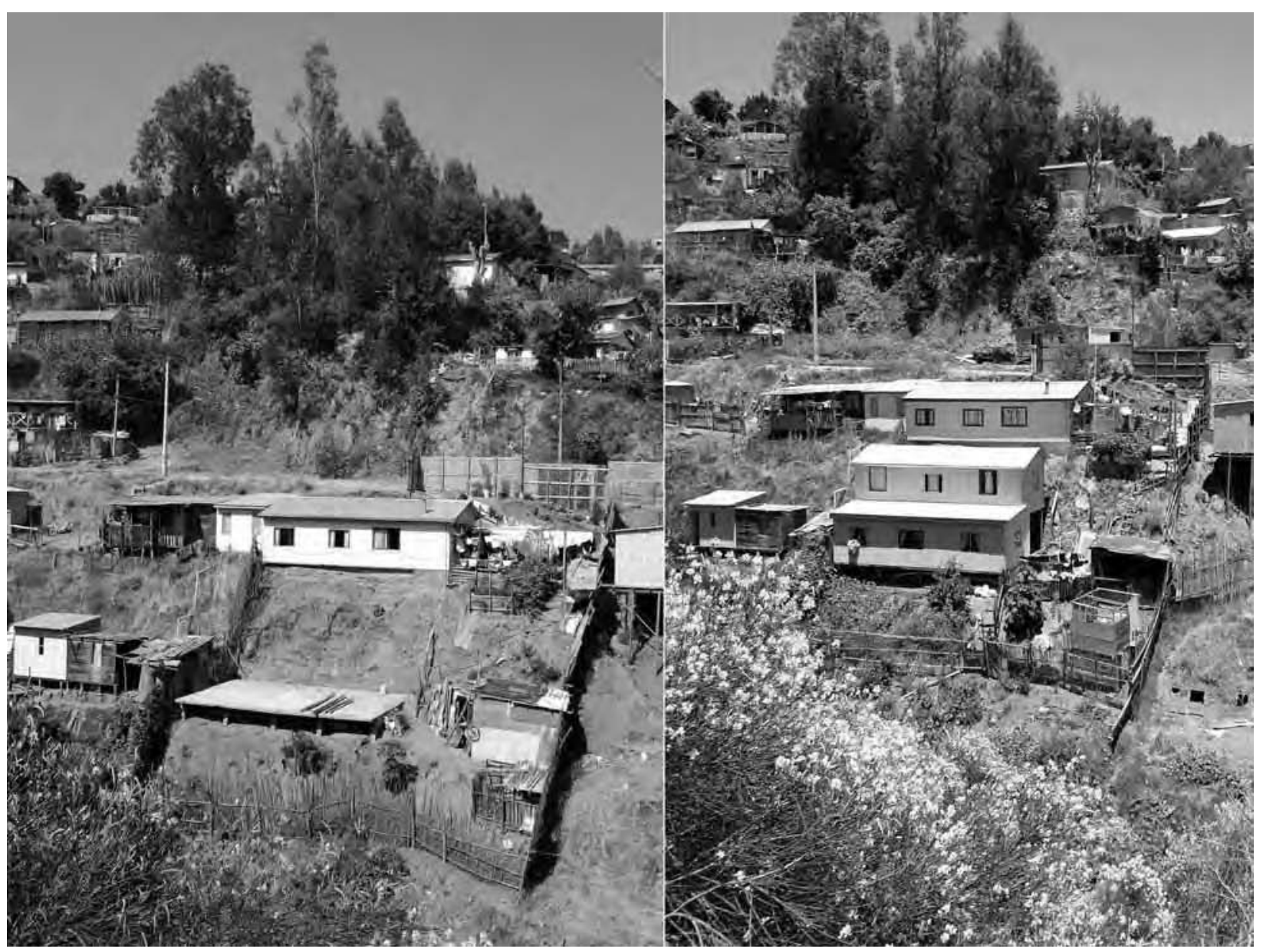

Fuente: Autores 
Por su parte, Reeves propone la bidonville (sinónimo de campamento o toma de terreno) como "un lugar de gestación urbana", donde la singularidad de la trama de la bidonville, lejos de ser un defecto, debiera servir de base a la oficialización futura del sitio y de la evolución de la ciudad. ${ }^{24}$

"Las bidonvilles o campamentos enriquecen la ciudad mediante un aporte constante de imágenes colectivas, que devendrán, si la bidonville deviene un barrio, en imágenes arquitectónicas". ${ }^{25}$

De esta manera consideramos que el hábitat informal se constituye como otra forma de hacer ciudad y que posee sus propias lógicas de apropiación y de ordenamiento que determinan su identidad, "implícita en relación a la vida cultural y social de la cual es el reflejo. Sin duda este es el punto fuerte de una concepción arquitectónica -sin arquitectos- que hace que el hábitat sea un acto cultural colectivo y singular". ${ }^{26}$

La expansión de la ciudad informal en Latinoamérica obedece a variados aspectos, uno de ellos es que la vivienda formal se ha vuelto inalcanzable para las familias de niveles económicos bajos. Como lo expone Davis, "la vivienda formal se volvió inasequible para cientos de miles de personas y la

24 Citado en Berenstein Jacques, 2001, p. 22.

25 Berenstein Jacques, 2001, p. 23.

26 Berenstein Jacques, 2001, p. 7. única alternativa que quedaba para la población era arriesgar la vida en los esteros, las zonas propensas a inundaciones, establecerse en los cauces de ríos" 27 . Así se comienzan a gestar nuevos procesos y formas de acceso al suelo urbano.

En el paisaje urbano latinoamericano hoy encontramos la informalidad del hábitat ${ }^{28}$ expresada en los siguientes ejemplos: las tomas de terrenos y/o campamentos en Chile, las villas miseria en Argentina, las favelas de Brasil, las chabolas de Perú, los cantegriles de Uruguay, los barrios ranchos en Venezuela, los barrios bajos en Colombia, las quebradas en Ecuador y las chacaritas de Paraguay. ${ }^{29}$

Esta tendencia ha dado lugar a lo que se conoce con el concepto de "favelización", "que ha alejado de nuestras mentes la idea de un siglo XXI de ciudades de cristal y acero, para presentarnos unas ciudades construidas directamente por la acción de la gente y en las que las infraviviendas, levantadas con materiales de desecho en zonas insalubres y sin ningún tipo de servicios, son el paisaje habitual". ${ }^{30}$

En Chile, particularmente la crisis de la vivienda obedece a varios aspectos que derivaron paulatinamente en diferentes formas informales de acceso al

27 Ver Davis, 2007.

28 Otros ejemplos internacionales: los slums en India, los shacks en África del sur, los gecekondu en Turquía.

29 Construcción informal: Río de Janeiro, 55\%; Bogotá, más de un $50 \%$.

30 Ministerio de Vivienda, 2010, p. 43. 
suelo urbano y a la vivienda. Este es un problema que comienza a gestarse en algunos centros urbanos del país desde mediados del siglo XIX, producto de la modernización y la industrialización. Así, encontramos las siguientes causas comunes:

1- Migración campo-ciudad, generada por la concentración de los servicios en los centros urbanos.

2- Hacinamiento en los centros urbanos, producto de un agolpamiento de la clase trabajadora y campesina en insalubres conventillos, cuartos redondos y cités.

3- Inaccesibilidad a la vivienda formal, ya que la población más pobre del país no tiene acceso a comprar viviendas ni terrenos.

4- Ineficacia e insuficiencia de las políticas y programas gubernamentales, generados para dar una solución eficaz a la problemática de la vivienda.

5- Existencia de terrenos baldíos en los centros urbanos y grandes propiedades en las periferias urbanas que suscitan la especulación.

6- Desregulación del mercado del suelo urbano.

\section{Acción pública en los campamentos}

En el año 1996, el MINVU mandata a la Universidad de Chile a realizar el primer "catastro de campamentos y asentamientos irregulares". Las cifras de dicho catastro arrojaron un total de 972 asentamientos precarios y/o campamentos, lo cual daría luz al programa "Chile Barrio". Luego la ONG Un Techo para Chile, en el año 2007, declaró que en Chile existían 533 campamentos a nivel nacional y 55 en la Región de Valparaíso, representando el $10.3 \%$ del nacional. Frente a esta realidad, el MINVU crea el "Programa de Campamentos" de la Secretaría Ejecutiva de Desarrollo de Barrios. En primer lugar el Programa de Campamentos elaboró una lista de "pistas de campamentos" en base a los catastros de la Línea de Atención de Campamentos o LAC MINVU (2007) y Un Techo para Chile (2007), obteniéndose un Catastro Primario que fue enviado a las SEREMIS MINVU con el objetivo de identificar territorialmente cada uno de los asentamientos y validar la existencia de cada una de las pistas entregadas. ${ }^{31}$

31 Ministerio de Vivienda, 2011. 
Así, a partir de las pistas entregadas por UTPCH y según el catastro realizado por el MINVU el año $2007^{32}$, en Chile existían 490 campamentos.

Hoy en día, de acuerdo al último catastro realizado por el MINVU, publicado en el "Catastro Nacional de Campamentos" en mayo de 2011, en Chile existen $706^{33}$ campamentos. Esto implica un total de 30.000 familias, siendo la Región de Valparaíso, la del Biobío y la Metropolitana las que concentran el mayor número, representando un $61 \%$ del total nacional.

En la región de Valparaíso se catastraron 160 campamentos, de los cuales el 50\% se ubica en terrenos estatales y municipales. Valparaíso y Viña del Mar concentran el mayor número de la región y del país, con un $69 \%$ sobre el total regional y un $15 \%$ sobre el nacional.

A nivel regional, la comuna de Valparaíso es la que concentra el mayor número, con 62 campamentos,

32 Este catastro nace de una primera lista de campamentos en base a catastros del LAC y de "Un Techo para Chile" en el año 2007, según la información solicitada a cada una de las municipalidades, dando como resultado un "Catastro Primario". Con este instrumento, cada SEREMI MINVU tenía por objetivo identificar territorialmente estos campamentos. El año 2007, “Un Techo para Chile" catastró 533 campamentos a nivel nacional y 55 en la Región de Valparaíso, representando el $10.3 \%$ nacional.

33 Esta cifra es muy superior a la del año 2007, debido al terremoto de febrero del 2010, el cual destruyó por completo varias ciudades del país. El gobierno, como medida paliativa, entregó viviendas de emergencia o mediaguas, que se constituyeron como campamentos. representando el 39\% de la región y Viña del mar con 47 campamentos alcanza el 29\%.

En el año 2008, el Ministerio de Bienes Nacionales en alianza con el Municipio de Valparaíso crea el "Convenio de Cooperación Valparaíso", programa de saneamiento de títulos de dominio, el cual beneficia con $100 \%$ de gratuidad el proceso de regularización del sitio a quienes se acerquen al Ministerio de Bienes Nacionales a solicitarlo.

Si bien es cierto que no todas las solicitudes llegan a buen término, podemos apreciar que la demanda no es menor, pues en el año 2010 el Ministerio de Bienes Nacionales recibió 2300 consultas por concepto de demandas de regularización de terreno y obtención de los títulos de dominio ${ }^{34}$; de éstos, 405 fueron regularizados, mientras otros aún están en espera y otros fueron definitivamente rechazados.

A pesar de que fueron las mismas familias quienes de forma particular presentaron estas solicitudes

34 Resumen Convenio Valparaíso 2010: Archivo facilitado por el Ministerio de Bienes Nacionales en la oficina del Convenio Valparaíso, en el año 2010. 
FIGURA 4. CATASTRO DE SITIOS IRREGULARES. EN RELACIÓN A ESTOS PORCENTAJES, LAS OUEBRADAS REPRESENTAN INDISTINTAMENTE UN ESTADO DE CONSOLIDACIÓN DIFERENTE: EL LITRE, UN ESTADO TERCIARIO; LAS CHANAS, SECUNDARIO Y LAS CAÑAS, PRIMARIO.
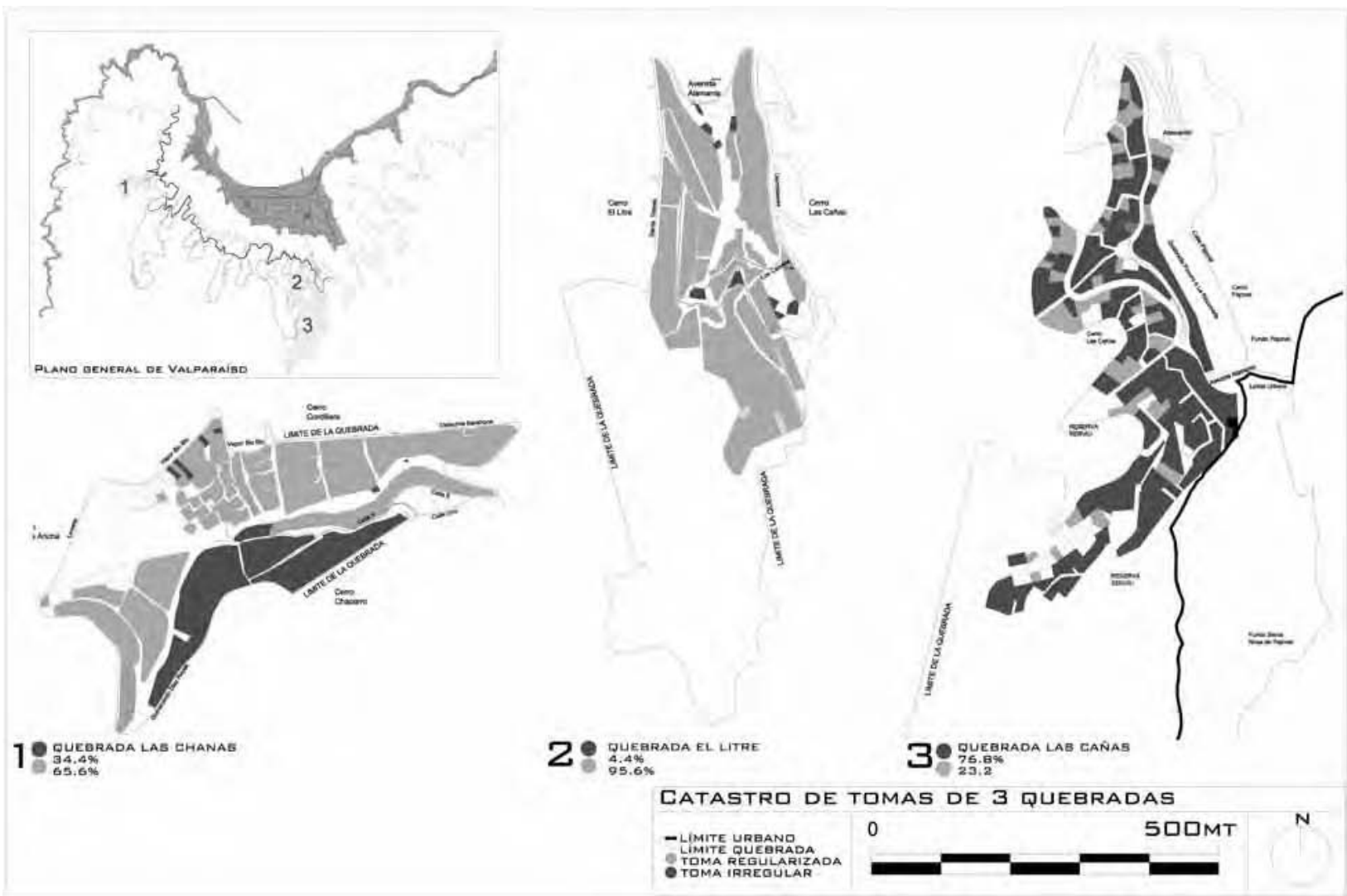

Fuente: Autores 
al Ministerio de Bienes Nacionales, aún existe un gran nivel de desconocimiento del convenio, debido a que el vínculo entre los diferentes estamentos estatales que intervienen en el proceso es casi inexistente. La centralización de cada entidad dificulta la interrelación de las mismas provocando confusión y desconocimiento en los solicitantes, quienes muchas veces renuncian al proceso porque la información no ha sido bien entregada, lo cual evidentemente dificulta el encuentro de las partes involucradas. Además, hay que agregar que los medios de difusión de la información no son los adecuados, puesto que la mayoría de la gente que vive en "campamentos" o en tomas no tiene acceso a internet, o muchas veces desconoce adonde debe dirigirse para efectuar dicho trámite.

Considerando lo anterior y con el objetivo de ampliar esta información, se realizó un catastro insitu en cada una de las tres quebradas estudiadas, determinando el número de terrenos irregulares que nacieron de tomas de terreno y que hoy en día se encuentran en situación irregular. Se cruzó la información recogida con los roles de las propiedades inscritas en el Servicio de Impuestos Internos, lo cual dio como resultado tres cartografías que muestran los porcentajes de formalidad e informalidad de cada quebrada.

\section{La toma de terreno en las quebradas de Valparaíso}

Definiremos "la toma" como la acción de ocupar y habitar ilegalmente un terreno, es "la posesión de un terreno sin ventas ni títulos" ${ }^{135}$, construyendo sobre él una casa, un rancho o una mediagua. Es una respuesta a una carencia de quienes no poseen otra posibilidad frente a la falta de habitación.

La toma de terreno en Valparaíso difiere de aquellas sucedidas en Santiago principalmente en la forma de acción, pues la toma santiaguina es una acción colectiva y la toma porteña es una acción familiar y/o de pequeños grupos.

En Santiago, cuando se habla de toma de terreno se hace alusión a una gran propiedad tomada por una colectividad que luego es subdivida en sitios o lotes por sus ocupantes. Ejemplo de ello son la toma de la Victoria (1957) y la toma de Peñalolén (1999). Sin embargo, en Valparaíso la palabra "toma" hace alusión a la posesión de una porción de terreno por parte de una familia y/o un pequeño grupo, y que luego puede adquirir un carácter colectivo en la medida que otras personas se tomen otras porciones de terreno cercanas al primer sitio tomado. Es decir, la toma porteña se diferencia de

35 Ministerio de Vivienda, 2010, p. 48. 
la santiaguina en su carácter incremental, que se formaliza en la adición de sucesivas pequeñas tomas familiares.

Las tomas de terrenos en Valparaíso han sido la forma principal de generación del hábitat informal y por medio del cual la ciudad ha crecido y se ha consolidado. Esta toma de carácter familiar y/o de pequeños grupos es la que ha originado los Conjuntos Residenciales Familiares (C.R.F). Lo entendemos en el sentido propuesto por Agier, quien los define como sistemas familiares de vivienda donde cada familia recompone y reconstruye una parte del medio urbano complejizándolo y dándole forma, generando así una red de interconexiones y ramificaciones residenciales, pero siempre ligadas a un conjunto visible. ${ }^{36}$

\section{Procesos que intervienen en la apropiación informal de las quebradas}

A partir de los antecedentes recogidos mediante los relatos de vida, se distinguen variadas causas que motivaron la ocupación de estos territorios en la ciudad de Valparaíso.

Agier, 2009.

\section{LA TOMA PARA DEVENIR DUEÑOS}

La motivación principal que resuena en cada relato es la más obvia y se sustenta en aquel dicho que todo chileno conoce, "el sueño de la casa propia", el cual aparece implícito en la mayoría de los relatos. Esto se ve claramente ilustrado en el testimonio de Don Luis y su esposa Jeannette, quienes habitan en la quebrada El Litre y aún no logran regularizar la tenencia de su sitio.

"Nosotros igual después del terremoto (1985) no queríamos seguir de allegados, queríamos tener algo propio, algo de nosotros, para los niños, por eso nos metimos aquí. No podíamos seguir en una pieza, esto a nosotros nos costó" (H.N., hombre, 56 años, El Litre).

Es decir, las familias visualizan en la toma la posibilidad de tener acceso a un terreno propio, que se convierta en un patrimonio familiar.

\section{La toma ante la falta de medios económicos}

La toma como solución habitacional se percibe como el único recurso viable para aquellas personas que no poseen otra posibilidad. Frente a la 
falta de recursos económicos, deben gestionar por sus propios medios la obtención de un lugar donde vivir.

Este es el caso de la Sra. Nancy de la quebrada Las Cañas, quien ha vivido siempre en la quebrada, pero que se tuvo que trasladar de su toma original a otra toma en la misma quebrada, a un sector más rural, fuera del límite urbano, en un costado del Fundo Santa Rosa de Pajonal.

"A mi no me quedó otra, si mi jubilación no me alcanza para arrendar. Aquí de a poquito hemos construido esta chocita con mi esposo [...] y para la ficha CAS no me alcanza, porque ve usted que soy vieja y si yo no tengo ya niños que cuidar, no tengo derecho a nada, así que voy a quedarme aquí no más" (H.F., mujer, 76 años, Las Cañas).

\section{LA TOMA COMO UNA OPCIÓN HABITACIONAL VIABLE}

Por otra parte, el hecho de tomarse un terreno en una quebrada se concibe como una ocupación viable, con más posibilidades de permanencia por presentarse como territorios de bajo avalúo fiscal, de fácil acceso, sin control municipal efectivo, de poca o nula oposición de posibles propietarios privados $^{37}$, y por ser territorios históricamente estigmatizados y catalogados popularmente como tierra de nadie. Esto se ejemplifica en el relato de la Sra. Juana, quien en innumerables ocasiones ha intentado contactarse con los propietarios de los terrenos donde ella ha habitado, sin obtener resultados ni oposición:

"aquí nadie nos molesta, esto está así desde que tengo uso de razón. Este es el fundo Santa Rosa Pajonal. [...] y de los 17 herederos, nosotros encontramos a una doctora en Santiago, pero ella no quiere saber nada de esto, porque dice que para poder vender tienen que estar todos juntos (herederos). y creo que andan para España, para Suecia, así que tendría que ser el gobierno no más" (H.F., mujer, 57 años, Las Cañas).

\section{LA TOMA EN LA QUEBRADA COMO LUGAR DE ORIGEN}

La quebrada como lugar de origen es la causa de ocupación más simple, ya que algunos vecinos son oriundos de ese lugar. La quebrada y la toma se constituyen como la única forma de vida que conocen. En el relato de la Sra. Trinidad se evidencia esta

37 Existen casos paradigmáticos de quebradas donde los propietarios nunca aparecieron u otras con propietarios reconocidos como Las Cañas, donde más de 150 familias aún ocupan terrenos privados y del SERVIU sin ser regularizados. 0 el caso de Rocuant, el cual era una toma donde nunca se pudo verificar el propietario, por lo cual todos los sitios se regularizaron. 
realidad, cuando en el año 1986 se realizaron los trabajos de continuación de la Avenida Alemania; se erradicaron 60 familias, sin embargo, ellas no se fueron de la quebrada sino que se relocalizaron.

"Yo soy nacida y criada aqui en este cerro, yo he vivido en dos diferentes terrenos, en tomas, en estos mismos lugares, yo vivía en un predio para allá pa' arriba. En el año 86 [...] desde esa vez expropiaron las casas [...] mi papá se tuvo que ir para allá arriba en los olivos, en el cerro, [...] porque en realidad les dieron unas monedas por el terreno pero no se quisieron ir de acá, se tomaron los sitios que estaban para allá, cortaron los árboles, todos se tomaron porque nadie se quería ir de este lado" (H.F., mujer, 54 años, Las Cañas).

\section{LA TOMA COMO SOLUCIÓN HABITACIONAL FRENTE A LA MIGRACIÓN}

La migración de familias a Valparaíso que no poseían una red social que amortiguara el desplazamiento y alojamiento, implicó que estas familias vieran en las quebradas la posibilidad de instalarse en la ciudad sin mayores costos. Tenemos que entender que las familias venían a la ciudad en busca de trabajo, por lo cual no poseían capital económico que les permitiera comprar y/o arrendar una propiedad. Este el caso de la Sra. Doraliza, quien llegó desde el sur del país.

"Yo me vine trabajando, yo soy del sur, de Concepción [...] con unos patrones muy buenos que tuve. Duré 20 años trabajando en esa casa, prácticamente desde los diez años. En ese entonces, el que fue mi compañero trabajaba en esa casa también y ahí nos conocimos y él vivía en este cerro, en el Cerro El Litre" (H.F., mujer, 78 años, El Litre).

Como podemos apreciar, las causas que motivaron la ocupación de las quebradas son muy variadas. Sin embargo, se reconocen dos procesos principales que originaron la migración hacia las quebradas de la ciudad: la movilidad familiar y los terremotos, que son los que aparecen con mayor recurrencia en los relatos.

\section{Movilidad familiar}

Con el concepto de movilidad familiar nos referimos a un tipo de movilidad residencial, que establece una lógica de ocupación administrada por las familias integrantes de la toma. Es un mecanismo solidario de acceso al suelo urbano, donde una persona o familia que se encuentra materialmente en posesión de un sitio, propone o invita a sus familiares y/o amigos a instalarse junto a ellos, en vista de que se encuentran en situación de necesidad o de crisis habitacional.

Esta forma de acceso a la toma genera los conjuntos residenciales familiares, ya que son los primeros ocupantes quienes asumen en su justa medida un rol de administradores del territorio de las 
quebradas, y son quienes toman la decisión de aceptar o rechazar a alguien nuevo, en la medida que son ellos quienes extienden la invitación de compartir un terreno.

Este rol de administrador puede ser asumido por un vecino cualquiera, o por un representante del barrio, como un dirigente vecinal.

Por ejemplo, la Sra. Trinidad de la quebrada Las Cañas fue erradicada de su toma inicial en la quebrada La Rinconada, y es un amigo quien la invita a instalarse en aquella quebrada. Ella nos relata lo siguiente:

"Un amigo que se había metido aquí, me dijo 'tómate aquí, cuando yo me quedé sin casa, porque hicieron el camino ahi en las palmeras" (H.F., mujer, 54 años, Las Cañas).

La Sra. Ximena de la quebrada El Litre cuenta que se encontraba de allegada en la casa de sus padres y fue su hermana, quien habitaba en la quebrada desde hace un tiempo, quien la invitó a vivir allí pues había un terreno que había quedado disponible luego de un incendio.

"Mira, cuando yo me vine a vivir, mi hermana mayor vive arriba, entonces como yo estaba de allegada donde mi mamá, me dijo: 'sabes ipor qué no te vas allá?, allá hay un terreno que se quemó. Aquí había una casa, pero no estaba toda la casa completa, había un pedazo de casa, y acá era pura zarzamora, entonces me dijo tienes que sacar la zarzamora y le dije ya po, y así empezamos a hacer poco a poco la casa, así llegamos aquí" (H.C.R.F., 51 años, El Litre).

En este caso, la movilidad residencial es estratégica y genera un beneficio recíproco. Por una parte, la Sra. Ximena y su familia obtienen una solución habitacional, posibilitada por la invitación de su hermana. Y por otra parte, su hermana se asegura con esta invitación la elección de su nuevo vecino, en este caso su propia hermana. Es decir, un familiar de confianza, con quien será más fácil consolidar la posesión del sitio.

De esta manera, la movilidad familiar es una práctica que está arraigada en la forma de vivir de los habitantes de las quebradas, replicándose de generación en generación, lo cual finalmente implica la consolidación de conjuntos de viviendas, que están agenciadas entre sí por medio de lazos familiares o amicales. Una familia que una vez fue invitada por un familiar, hace lo mismo por otra. La Sra. Ximena continúa diciendo:

"Por ejemplo, yo le dije a mi hija que se hiciera una piececita aqui al lado de la mía en el patio, porque mi hija es madre soltera, entonces no tenía dónde vivir con su pareja, pero yo le dije que tenía que hacerse una piececita, así ella está más tranquila y yo también en su propia casa" (H.C.R.F., 51 años, El Litre).

Sin embargo, a veces este rol de administrador lo asume algún representante del barrio, por ejemplo un dirigente vecinal, quien vela por los intereses del grupo. 
Este es el caso de la señora Valeria, de la quebrada Las Cañas, quien en su calidad de presidenta de la junta de vecinos nos cuenta que es ella quien decide si la toma puede seguir creciendo o no, determinando si es posible que se instalen nuevas familias.

"Yo controlo. La gente sabe que aquí no puede ponerse nadie más, no hay más espacio y de ponerlos igual sería un riesgo, ya no se puede más. Tratamos nosotros, los mismos vecinos de proteger que no se pongan más casas [...] Ha venido harta gente a tratar de tomarse otros terrenos y nosotros les hemos dicho que no" (H.D., mujer, 37 años, Las Cañas).

Finalmente, la movilidad familiar, en tanto que proceso es constituyente de la historia familiar de los habitantes de las quebradas, es un relato que se transmite y se hereda, que busca mediante su repetición ese arraigo a un territorio inasible, donde ser propietario es un sueño constante e implica la aceptación de una historia común. Como es el caso de Cristofer, un joven de la quebrada Las Chanas:

"Yo vivo aquí desde que nací, mi papá vivía antes en [el cerro] Placeres, la familia de mi papá y la familia de mi mamá viven aquí. Justo aquí arriba viven los padres y las hermanas, antes vivian un poquito más abajo, como adentro de la quebrada. Pero después se vinieron a vivir a este terreno [...] mire, todo esto es un puro terreno que es de mi tata, aquí hay 5 casas, no sé cuántos metros cuadrados, pero debe tener más o menos 50 de frente y 20 para atrás más o menos." (H.N., hombre, 16 años, quebrada Las Chanas).

Esta forma de distribución de los terrenos determinada por la movilidad residencial, comprueba que las tomas en las quebradas no se constituyen como tomas masivas, por el contrario, son tomas de grupos pequeños y/o familiares, que han generado un proceso de ocupación evolutivo.

De esta forma, hoy las quebradas presentan una densidad habitacional que ha sido dirigida y controlada por sus propios habitantes, mediante la autorización o negación de la instalación de nuevas tomas, es decir, de nuevas familias. Sus propios habitantes son quienes deciden cómo distribuir los retazos de terreno.

\section{Los terremotos}

La condición que presentaban las familias previamente a un terremoto era de allegados en casas de amigos y/o familiares, o de arrendatarios de piezas en edificios y/o casas, que quedaron inhabitables tras el siniestro.

Frente a esta situación de emergencia, la toma de terreno se presenta como la única solución habitacional rápida, posible y al alcance de las familias de bajos ingresos. 
Históricamente la ciudad de Valparaíso ha sido golpeada por sucesivos terremotos ${ }^{38}$, sin embargo, los que son de nuestro interés son aquellos sucedidos desde principios del siglo XX, terremotos que tuvieron una fuerte incidencia en lo que respecta a la ocupación informal de las quebradas no-consolidadas. Éstos generaron una movilidad de la población más desfavorecida y pobre de la ciudad, que habitaba en conventillos, cités y cuartos redondos situados en los cerros y en el plan de Valparaíso, quienes buscaron en las quebradas nuevos territorios donde asentarse.

Producto de la creciente actividad marítima y comercial, Valparaíso, desde mediados del siglo XIX, experimentó una acelerada modernización, la cual influyó en el desarrollo del espacio urbano y sus infraestructuras. De esta manera, el primer terremoto de nuestro interés es el de 1906, ya que vendría a enlutar este creciente desarrollo con la casi completa destrucción del plan de la ciudad.

En relación a esto, encontramos un primer indicio en el relato de la Sra. Ana y sus hermanos, quienes viven en la quebrada Las Chanas y recuerdan que

38 El terremoto de 1647 es el primer evento telúrico que se registra en la historia de Valparaíso, sin embargo, son 12 eventos de este tipo que afectaron a la ciudad hasta nuestros días, ellos sucedieron en los años: 1647, 1730, 1751, 1822, 1829, 1851 ,1896, 1906, 1965, 1971, 1985 y 2010. su abuelo junto a su padre y su tío llegaron a Valparaíso desde Nirivilo ${ }^{39}$.

"Mi padre era de un pueblo del sur que se llama Nirivilo, que antes era (pertenecía) de Constitución. Él llegó por el terremoto de 1906. Dice que se vino porque el papá trabajaba en construcción y aquí quedó todo botado Valparaíso, entonces mucha gente emigró", (H.F., mujer, 75 años, Las Chanas).

La Sra. Ana y su familia han sido testigos presenciales de los acontecimientos y procesos vividos en la quebrada luego de cada terremoto. Ella nos explica que el fenómeno de ocupación de la quebrada mediante tomas de terrenos, se repitió intermitentemente con los sucesivos terremotos, modificando el paisaje de la quebrada. Ella continúa diciendo:

"Mire, aquí habia un bosque (señalando el lugar con las manos), después del terremoto del 85. Y antes con el del 65, por ahí vino uno parece, después el 71, bueno, la cuestión es que ahi empezaron a instalar las mediaguas y las tomas, o sea empezaron a tomarse [...] Después de los terremotos, así como que se vienen [nuevos ocupantes]" (H.F., mujer, 75 años, Las Chanas).

39 Nirivilo, localidad ubicada en la VII región del Maule-Chile. Antiguamente perteneciente al Departamento de Constitución. 
El segundo terremoto de nuestro interés es el de 1965. A esa fecha, según el censo nacional de 1960, la ciudad de Valparaíso presentaba un déficit de 52.803 viviendas, de las cuales 9.871 eran no-reparables y 32.547 ofrecían deficiencias, aunque susceptibles de ser reparadas. De esta manera, con el terremoto de 1965 quedaron 15.000 casas destruidas, según el cálculo realizado por los técnicos de la municipalidad, y al mismo tiempo se estimó que el 90\% de las viviendas de la ciudad quedaron dañadas ${ }^{40}$.

En este contexto encontramos el relato de la señora María, quien llegó a la quebrada El Litre tras el terremoto de 1965 y se instaló con una mediagua entregada por la municipalidad. Inicialmente, es una toma de terreno avalada por el municipio, la cual es regularizada el año 1993 por autogestión de un grupo de vecinos que se encontraban en la misma situación. Ella lo relata de la siguiente manera:

"Yo llegué aquí con el terremoto del 65, antes vivíamos en una piececita que arrendábamos en el Cerro Merced, en invierno nos llovíamos y con mi hija abríamos unas zanjas en el piso para que el agua pasara al subterráneo, para no tener mojada la pieza. Y luego con el terremoto quedó peor, así que tuvimos que buscar otro

40 Diario La Unión, 3 de abril de 1965. Datos recogidos del Censo Nacional de 1960. lugar para vivir. El alcalde me dijo que podía escoger el terreno que quisiera y aqui instalé la mediagua, que en ese tiempo había que ir a buscarla a Puertas Negras. [...] En realidad fue mi papá y un caballero, que me instalaron la mediagua aquí, pero asi para el otro lado, con la puerta hacia el patio del terreno. Antes yo tenía abajo un jardín, pero después mi hijo se hizo la casa" (H.C.R.F., mujer, 90 años, El Litre).

Frente al déficit habitacional suscitado tras el terremoto, el alcalde de la época, Juan Montedónico, anuncia que Valparaíso tendrá su propio plan de vivienda, llamado Operación mediagua"41, de las cuales la Sra. María fue una de las beneficiarias.

El tercer terremoto de nuestro interés es el de marzo de 1985, el cual sacudió la zona central de Chile, destruyendo 142.489 viviendas, marcando un déficit histórico que llegó a más de un millón de unidades a nivel nacional ${ }^{42}$.

En este contexto encontramos el relato de don Héctor, quien era arrendatario de una pieza en el centro de la ciudad y llegó a vivir a la quebrada El Litre por invitación de sus suegros. Este es un caso simultáneo donde las dos causas comparecen, es decir, el terremoto y la movilidad familiar. En vista de la necesidad de habitación de la familia de don

41 La operación estaba destinada a la habilitación de viviendas mínimas, no de carácter permanente, pero destinadas a darle techo a los damnificados en el menor tiempo posible". Diario La Unión, 3 de abril de 1965.

42 Navarro, 2005, p. 12. 
Héctor, la toma es una forma de apoyo económico y social. Aquí es cuando comienza a gestarse uno de los conjuntos residenciales familiares que presentaremos más adelante, los cuales son legalizados en 1993.

"Nosotros empezamos a arrendar a un tío allá al frente, en el cerro Merced y después del terremoto del 85, como ella (la esposa) estaba embarazada la vine a dejar acá, donde mi suegro, porque yo tenía que preocuparme del taller, porque yo tenía el taller allá abajo en la Avenida Independencia (centro de la ciudad). Como eso se cayó, ese edificio, cuando llegue acá ya mi suegro estaba picando (el cerro) y me dijo que me quedara acá con mi señora para que no gastara en arriendo, porque pagaba dos arriendos, el local y la casa. [...] Él (el suegro) me cedió este terreno, él está aquí como del 45 (1945), por ahí empezaron las tomas aquí [...] y yo estoy desde el año 85, el mismo día del terremoto" (H.C.R.F., hombre, 51 años, El Litre).

De la misma manera la señora Lucinda llega a la quebrada El Litre, donde su condición anterior al terremoto era de arrendataria de una pieza en el plan. Ella nos relata:

"Yo llegue acá porque antes vivía en el plan y en el año 85, cuando fue el terremoto, yo quedé prácticamente en la calle, la casa se cayó donde yo vivía [...] yo arrendaba pieza, en esos tiempos vivía con mis dos

ARTíCULO: Ciudad y hábitat informal: Las tomas de terreno y la autoconstrucción en las quebradas de Valparaíso / Andrea Pino Vásquez, Lautaro Ojeda Ledesma niños mayores, sola, porque tuve un marido que también desapareció, entonces seguí luchando sola, trabajando; después quedé sin trabajo, vino el terremoto, se cayó la casa y quedamos en la calle" (H.F., mujer, 58 años, El Litre).

El terremoto mencionado con mayor recurrencia es el de 1985. Según el Centro de Investigación Social de Un Techo Para Chile, el promedio de antigüedad de los campamentos es de 18,3 años, es decir, la media de los campamentos se establecieron justamente después del terremoto de $1985^{43}$. Arellano alude que las tomas de terreno en los sectores altos de Viña del Mar también tienen su origen en el terremoto de $1985^{44}$.

\section{Conjuntos residenciales familiares (C.R.F.)}

El hábitat informal en las quebradas define un modelo urbano de escala familiar y barrial propio a ellas, que se desarrolla como proyecto familiar y comunitario, siendo el resultado de una exploración, apropiación y construcción, donde las modificaciones, renovaciones y ampliaciones son proyectos que nacen y se consolidan desde la práctica social.

De esta manera, la práctica social, en términos de informalidad, origina una forma o modelo

43 Ahumada, López y Quintana, 2003, p. 26.

44 Arellano, 2005.

revista invi № 78 / Agosto 2013 / Volumen № 28: 109-140 131 
particular de apropiación en las quebradas, el cual se materializa mediante los Conjuntos Residenciales Familiares (C.R.F), los cuales definiremos como sistemas familiares de viviendas donde cada familia recompone y construye una parte del medio urbano complejizándolo y dándole forma, generando así una red de interconexiones y ramificaciones residenciales, pero siempre ligadas en un conjunto visible. El conjunto es el resultado de una organización familiar extendida ${ }^{45}$, la cual explica la manera azarosa y compleja que poseen estos agrupamientos de viviendas, de piezas o de cuartos dispuestos sobre un mismo sitio.

Como mencionamos anteriormente, la característica principal de las tomas en las quebradas es que se constituyen como micro tomas familiares, a partir de unidades habitables y de escala variable donde inicialmente una familia se apropia de una parte del territorio y después la subdivide para dar lugar a otro miembro. Se conforma de esta manera una vecindad familiar, donde varias casas interconectadas entre ellas logran la consolidación parcial de un fragmento de quebrada, que influirá directamente en la consolidación de los espacios públicos inmediatos al C.R.F. Cada uno posee un promedio de 3 viviendas, con un máximo de 6 . Por otra parte, los habitantes gestionan y dotan al sitio de

45 Definición según la Biblioteca del Congreso Nacional. todas las instalaciones básicas de agua, electricidad y alcantarillado, para luego ir formalizándolas y/o consolidándolas en una acción conjunta de los vecinos.

Estos C.R.F. se constituyen como una forma y modelo informal de construcción de ciudad en el sentido planteado por Borja: "En las periferias de las grandes ciudades latinoamericanas aparecen nuevas dinámicas de ocupación del territorio en forma de asentamientos que con la organización y la autogestión tratan de construir ciudad y no solo viviendas precarias". 46

Este modelo informal autogestionado y autoconstruido es un claro ejemplo de transgresión a la lógica formal. Paquot, ante las transgresiones desarrolladas en la ciudad, señala que más allá del estatus jurídico de éstas importa el "acto colectivo que otorga a estos espacios una dimensión social y pública"47. Salcedo indica que "Certeau expresa la misma preocupación de Foucault con las formas microscópicas que organizan a la sociedad, pero mientras la reflexión de Foucault se centra en la microfísica del poder, Certeau se centra en la microfísica de la resistencia, la cual está presente en todo contexto social y por ende en todo espacio"48, por lo cual podría asumirse que los C.R.F. son una 
FIGURA 5. C.R.F. PÉREZ, EN QUEBRADA EL LITRE. PROCESO DE OCUPACIÓN EVOLUTIVA DEL SITIO.

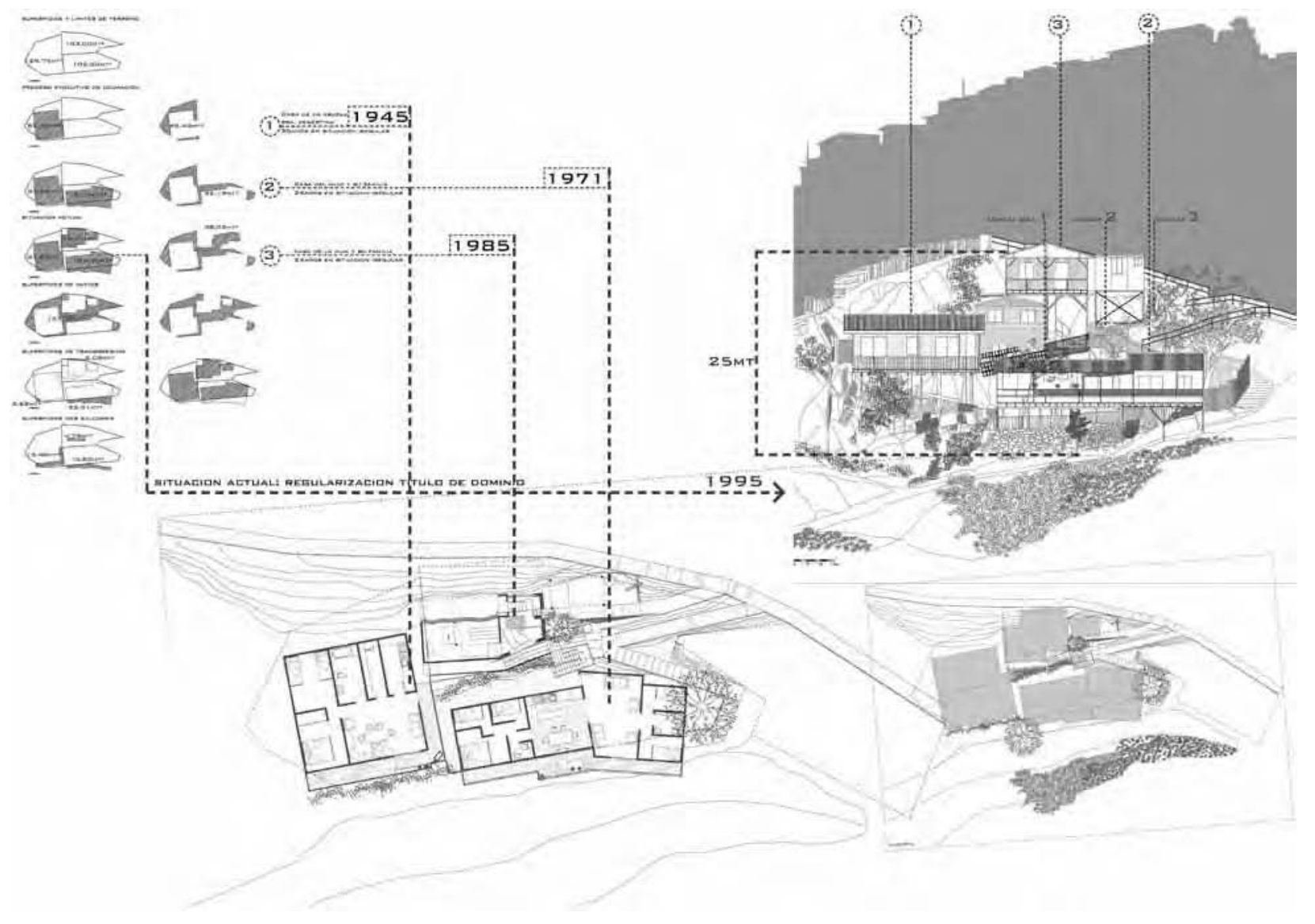

Fuente: Autores 
FIGURA 6. C.R.F. CARVAJAL, EN QUEBRADA EL LITRE. PROCESO DE OCUPACIÓN EVOLUTIVA DEL SITIO.

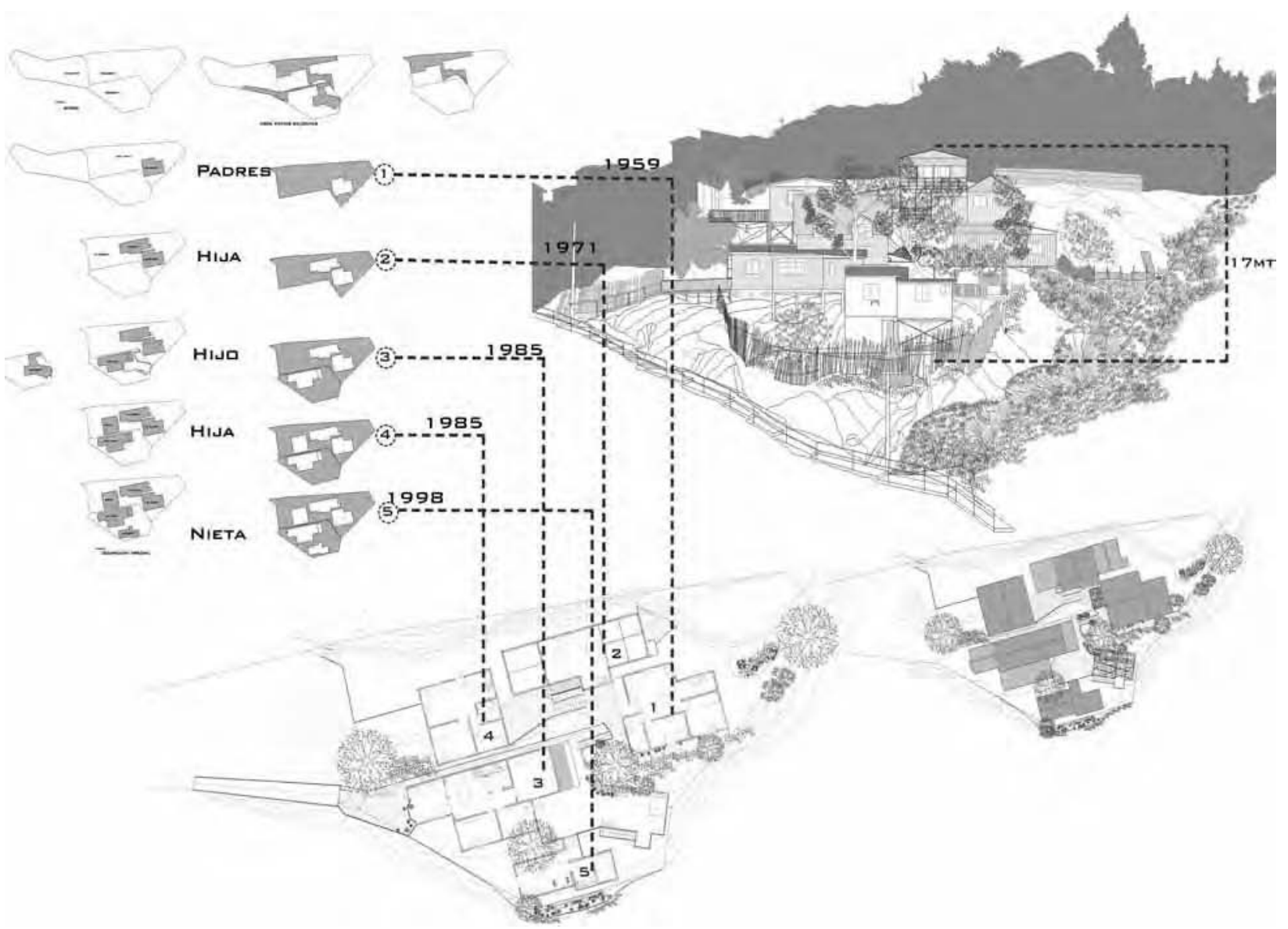

Fuente: Autores 
forma microscópica de resistencia al modelo for$\mathrm{mal}^{49}$, que los excluye y segrega.

Así, los C.R.F. se presentan como pequeños proyectos de recomposición urbana. Valoramos el hecho que han logrado consolidar, desde la informalidad, tramos de quebradas dotándolas de todos los servicios básicos, conectándolas con la ciudad planificada. Son recomposiciones a manera de mosaico urbano, que en conjunto logran abarcar la totalidad del territorio de la quebrada, consolidándola como un barrio abierto que permite la integración de sus habitantes a la ciudad.

La complejidad urbana y constructiva que presentan los C.R.F., construyen un paisaje evolutivo, supeditado a factores socio-culturales, factores que se expresan mediante la movilidad familiar y el ejercicio de la soberanía comunitaria.

- La movilidad familiar: como señalábamos anteriormente, obedece al traslado de una familia hacia una quebrada por medio de la invitación de un familiar o amigo. Esta movilidad genera que los grupos familiares desde un inicio se instalan agrupados en un territorio virtualmente delimitado.

- Soberanía comunitaria: tiene que ver con el control de la llegada de nuevas familias a la toma. Cuando la quebrada es percibida por sus habitantes como un barrio, ellos son quienes deciden si aceptan o no a nuevos ocupantes. Cuando la

49 Foucault, 1980 y Certeau, 1990. quebrada ha alcanzado un nivel de consolidación terciario, los habitantes adjuntan los retazos de terrenos a sus sitios, con el objetivo de no dejar sitios disponibles a nuevos ocupantes desconocidos.

- Construcción progresiva de la casa: la casa inicialmente se concibe como un fragmento de lo que ella podría llegar a ser. Se encuentra en un estado de proyecto inconcluso. Es una construcción a la medida, que sostiene una capacidad incremental. Esta capacidad es la que le otorga a este tipo de hábitat, esa manera de ser múltiple y variada, dando pie a que éstas se transformen constantemente.

- Apropiación orgánica del sitio: se refleja en la construcción de patios, jardines, terrazas y senderos que interconectan las casas entre sí. Esta apropiación obedece tanto a las características propias del sitio (tamaño, topografía, pendiente, calidad de suelo), como a las inventadas por sus propios habitantes, en ausencia de características naturales adecuadas para la construcción. La topografía de las quebradas es escarpada y de gran pendiente, la mayoría supera los $50^{\circ}$. Frente a esto, la construcción es aérea, con terrazas y pasajes que van construyendo la altura de la pendiente alcanzando a las viviendas situadas en cotas superiores. La trama de circulaciones entre las viviendas inicialmente es precaria, con senderos y escaleras moldeadas directamente en la tierra, hasta que se consolidan como patios comunes, cada uno con su 
especificidad (patio del agua, hortalizas, tendedero, etc.). De esta forma, lo que el C.R.F. se consolida se materializa con la instalación de un cerco común a las viviendas. Así, se alcanza la consolidación absoluta cuando el sitio o los sitios compartidos son regularizados y reconocidos como propiedad de la familia (lo que no implica que la casa no siga siendo irregular).

\section{Los C.R.F. y sus tres escalas de intervención}

Se concluye que los C.R.F. son el producto de una apropiación socio-espacial. Lefebrve sostiene que un grupo se apropia de un espacio natural cuando lo modifica en función de sus necesidades y posibilidades, y en el caso de los C.R.F., ésta se expresa materialmente en tres escalas sucesivas: urbana, barrial y familiar.

Estas escalas implican un arraigo socio-espacial que se va construyendo en la medida que las familias se van apropiando de la quebrada, construyendo un paisaje que está conformado por lugares que "se transforman en centros de significados y en símbolos que expresan pensamientos, ideas y emociones de muy diversos tipos. El paisaje, por tanto, no sólo nos muestra cómo es el mundo, sino que es también una construcción, una composición de este mundo, una forma de verlo". 50

Así, la construcción social del paisaje de las quebradas se expresa social y espacialmente, produciendo una urbanización informal en constante evolución. Busquets indica que los barrios producidos por una urbanización informal son "una forma de crecimiento que se apoya en la transformación de suelo 'rústico' a 'urbano' a través de la simple definición de las parcelas que, a su vez, son el soporte de la construcción de las viviendas sin ningún tipo de urbanización." ${ }^{51}$ Y que luego, frente a las demandas cotidianas, los habitantes comienzan a dotar de servicios a la vivienda. Así, en la medida que ciertas necesidades primariamente familiares se hacen extensivas a nivel de barrio y se buscan soluciones compartidas, el barrio comienza un proceso de consolidación.

Este crecimiento y definición parcelaria en las quebradas se expresa materialmente en tres escalas territoriales complementarias, las cuales están en constante transformación.

- La primera es una escala urbana que se constituye como "la toma de posesión de un lugar", sea por una colectividad, por un pequeño grupo o de forma individual. En esta escala se lotean los terrenos, definiendo así los sitios, donde hay un primer intento de

50 Nogué, 2007, p. 12.

51 Busquets, 1999, p. 78. 
distribución y trazado del espacio público, definiendo vías de acceso y espacios de recreación, lo cual implica una auto-organización de la parte del grupo o familia. Es la etapa en que se traza y se excava el cerro desde donde se desprende la vivienda.

Con respecto a esto, la Sra. Ernestina, de la quebrada El Litre, quien vive desde el terremoto de 1965 en el sector comenta:

"yo me acuerdo cuando llegamos. Aquí éramos los topos (risas)... imagínese, era un cavar y cavar el cerro, para poder tener un pedacito de sitio plano [...] así nos decían a nosotros los vecinos de al frente: 'los topos"' ( H.F., mujer, 78 años, El Litre)

- La segunda es una escala familiar o personal, que se constituye con la autoconstrucción de la casa, sea una pieza, una mediagua o un rancho. Es un acto no planificado, realizado sin permisos, ni con las regulaciones técnicas que establece la ley, sino que se constituye en la inmediatez con el medio natural, el paisaje y con los medios económicos disponibles. Es un proceso evolutivo de larga duración, donde la casa es un proyecto inconcluso.

La casa de la Sra. Trinidad, en la quebrada La Rinconada, comienza a partir de la unidad básica, "una pieza", que luego se cambia por una mediagua, hasta que hoy en día la casa pierde su forma primigenia en las continuas ampliaciones que le suceden con el tiempo.
"Todo esto es de nosotros, lo hicimos nosotros, todos cooperamos, y el caballero sabía de construcción. Antes había sólo una pieza y se le vino el cerro abajo y tuvimos que empezar de nuevo. Esta es una mediagua que compramos y después nos agrandamos para cada lado, para allá y para acá, este es el sector más firme para construir, porque está alejado del cerro" (H.F., mujer, 54 años, Las Cañas).

- La tercera es una escala de barrio: fase de apego territorial que se constituye con la auto-urbanización informal del espacio de carácter público común a la quebrada, en pos de una mejora del entorno de la vivienda. Esto puede implicar la instalación de redes básicas de suministro de agua y de electricidad, así como también el alcantarillado. Asimismo, el mejoramiento o creación de equipamientos de uso público.

"Fuimos a la muni, o sea la presidenta, ella ayudó harto para que pusieran los postes y hacer que siguiera la huella. Llegaron camionadas de huevillos a la esquina, camionadas de cemento, trajeron todo los de la municipalidad y la mano de obra la tenían que poner los vecinos, claro, así hicimos todo acá. Todos los vecinos se levantaban temprano a 'encementar', a soldar, mi marido es soldador, él hizo esa baranda de la huella (pasaje), porque igual hay hartos niños y se necesitaba, él llegaba de la pega y hacía unos pinchazos" (H.C.R.F., mujer, 51 años, El Litre). 
Consideramos que esta es la tercera y la última escala de intervención en Valparaíso, porque esta comienza a gestarse cuando las dos escalas previas ya están aseguradas y porque determinará la consolidación de las tomas en las quebradas.

\section{Conclusión}

Se concluye que la tomas de terrenos, al nacer de una segregación socio-espacial sustentada en la desregulación del suelo urbano, forman parte de las construcciones informales latinoamericanas, pues han construido durante años una ciudad paralela sustentada en lo que Turner ha definido como "sistema de información y decisión laterales" 52 , que en los términos de Certeau y Foucault podrían entenderse como un sistema de resistencia creativa ante la exclusión.

La toma de terreno y el hábitat informal tanto en Chile como en el resto de Latinoamérica tienen como factor común su carácter incremental y de agenciamiento de partes, producto de la acción directa de la gente, que Davis ha definido como "favelización". En este contexto y gracias a los relatos de vida que hemos recogido, hemos podido constatar que la toma de terrenos en las quebradas de Valparaíso se diferencia de la toma santiaguina en cuanto ésta se genera en un periodo indeterminado, formalizándose poco a poco gracias a la adición de pequeñas tomas familiares, que

52 Turner, 1977.

138 revista invi № 78 / Agosto 2013 / Volumen Nº 28: 109-140 responden a una lógica de movilidad familiar generalmente asociada a los terremotos. En este contexto la toma porteña, al ser paulatina, se diferencia de la santiaguina en cuanto no tiene organización socioespacial. Es por ello que la construcción social del paisaje de las quebradas de Valparaíso constituye un modelo de barrio abierto y de escala variable sustentado en el modelo de soberanía comunitaria de los C.R.F., que en sí son producto de una red de procesos socio-espaciales evolutivos.

Si consideramos que los C.R.F. son enriquecedores de la ciudad, en la medida que son la consolidación formal de procesos socioculturales, también debiésemos considerar los riesgos inminentes que presentan las quebradas, las cuales podrían ser controladas mediante la implementación de proyectos específicos de consolidación, tanto de la vivienda como de los espacios públicos.

\section{Bibliografía}

AGIER, Michel. Esquisses d'une anthropologie de la ville, Lieux, situations, mouvements. Louvain-laNeuve, Belgique, Bruylant-Academia. 2009. 158 p. ISBN 978-2-87209-963-4.

---- L'invention de la ville, banlieues, township, invasions et favelas. Paris, France, Éditions des 
Archives Contemporaines, Une pensée d'avance. 1999. 176 p. ISBN 978-9-0570-9014-1.

AHUMADA, Juan; LÓPEZ, Patricia y QUINTANA, Carolina. Catastro de campamentos, región metropolitana. CIS 2003. [En línea]. Centro de Investigación Social. 2(3): 24-29. 2003. ISSN 0718-5561. Disponible en: http://www.techo.org/wp-content/ uploads/2013/02/catastro-2003.pdf.

ARELLANO, Nelson. Historia local del acceso popular al suelo. El caso de la ciudad de Viña del Mar. [En línea]. Revista INVI. 20(54): 56-84. 2005. ISSN 0718-1299. Disponible en: http://revistainvi. uchile.cl/index.php/INVI/article/view/328/892.

BERENSTEIN JACQUES, Paola. Les favelas de Rio, un enjeu culturel. Paris, France, L'Harmatan. 2001. 176 p. ISBN 2-7475-0184-1.

BERTAUX, Daniel. L'enquête et ses méthodes, le récit de vie. Paris, Francia, Armand Colin. 2010. 127 p. ISBN 978-2-200-24818-5.

BOLÍVAR, Teolinda. Hacedores de ciudad. Caracas, Venezuela, 1995. 162 p. ISBN 980-00-0900-0.

BORJA I SEBASTIÁ, Jordi. La ciudad conquistada. Madrid, España, Alianza Editorial. 2003. 381 p. ISBN 84-206-4177-4.

BUSQUETS i GRAU, Joan. La urbanización marginal. Barcelona, España, Edicions UPC. 1999. 254 p. ISBN 84-8301-325-8.

CERTEAU, Michel de. L'invention du quotidien. 1 Arts de faire. Paris, Folio Essais. 1990. 350 p. ISBN 978-2-07032576-4.
DAVIS, Mike. Planeta de ciudades miseria. Madrid, España, FOCA ediciones y distribuciones generales. 2007. 283 p. ISBN 978-84-95440-96-9.

DI MÉO, Guy. Géographie sociale et territoires. Paris, France, Editions Nathan. 1998. 320 p. ISBN 2-09-190907-6.

FERNÁNDES, Edesio. Consideraciones generales sobre las políticas públicas de regularización de asentamientos informales en América Latina. [En línea]. Eure. 34(102): 25-38. Agosto 2008. ISSN 07176236. Disponible en: http://dx.doi.org/10.4067/ S0250-71612008000200002.

FOUCAULT, Michel. Microfísica del poder. Madrid, Las ediciones de La Piqueta. 1980. 189 p. ISBN 84-7443-017-8.

HARDOY, Jorge E. y SATTERTHWAITE, David. La ciudad legal y la ciudad ilegal. Buenos Aires, Argentina, Grupo Editor Latinoamericano S.R.L. 1987.103 p. ISBN 950-9432-88-1.

LEFEBVRE, Henri. La production de l'espace. 4a edición. Paris, France, Anthropos. 2000. 487 p. ISBN 2-7178-3954-2.

LINDÓN, Alicia. La construcción social del territorio y los modos de vida en la periferia metropolitana. [En línea]. Territorios. (7): 27-41. 2002. ISSN 0123-84-18. Disponible en: http://www.redalyc. org/articulo.oa?id=35700703.

MINISTERIO DE VIVIENDA, Gobierno de España. Las tomas de tierras urbanas en Latinoamérica hoy: problema o solución. Madrid.

revista invi № 78 / Agosto 2013 / Volumen № 28: 109-140 139 
España, Ministerio de Vivienda. 2010. 256 p. ISBN 978-84-96387-48-5.

MINISTERIO de Vivienda y Urbanismo. Catastro Nacional de Campamentos: primera etapa, mayo 2011. Santiago, Ministerio de Vivienda y Urbanismo. 2011. 50 p.

NAVARR0, Mario. Housing finance policy in Chile: The last 30 years. [En línea]. Land lines. 17(3): 12-14. 2005. [Fecha de consulta: 10 septiembre 2011]. Disponible en: http://www.lincolninst. edu/pubs/1042_Housing-Finance-Policy-in-Chile--The-Last-30-Years.

NOGUÉ, Joan. El paisaje como constructo social. En: NOGUÉ, Joan. La construcción social del paisaje. Madrid, España, Biblioteca Nueva. 2007. p. 11-24. ISBN 978-84-9742-624-4.
PAQUOT, Thierry. L'espace public. Paris, La découverte, 2009. 126 p. ISBN 978-2-7071-5489-7.

SALCED0, Rodrigo. El espacio público en el debate actual: Una reflexión crítica sobre el urbanismo post-moderno. [En línea]. Eure. 28(84): 5-19, septiembre 2002. ISSN 0717-6236. Disponible en: http://dx.doi.org/10.4067/ S0250-71612002008400001.

TARDIN COELHO, Raquel Hemerly. Los paisajes de la ciudad oculta. En: NOGUÉ, Joan. La construcción social del paisaje. Madrid, España, Biblioteca Nueva. 2007. p. 197-216. ISBN 978-84-9742-624-4.

TURNER, John F.C. Vivienda, todo el poder para los usuarios. Madrid, España, Hermann Blume. 1977. 171 p. ISBN 84-7214-124-1. 



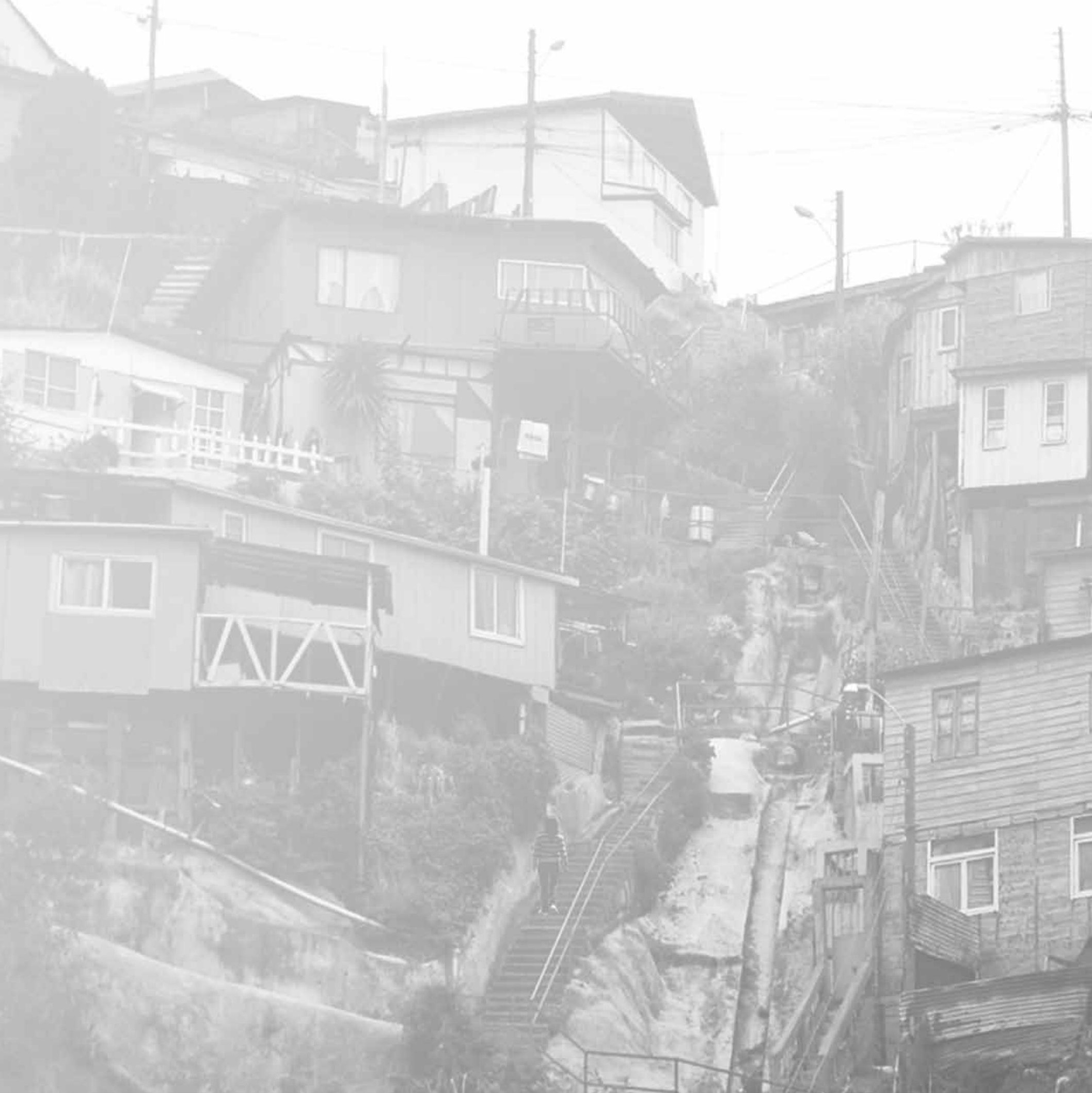

